\title{
Effect of Bacillus subtilis on phosphorus uptake by cucumber as affected by iron oxides and the solubility of the phosphorus source
}

\author{
Ana M. García-López and Antonio Delgado \\ Agroforestry Science Department, University of Seville. Ctra. Utrera km1, 41013 Seville, Spain \\ e-mail: adelgado@us.es
}

\begin{abstract}
In this work, we examined the effects of Bacillus subtilis strain QST713 by assessing plant P uptake from variably $\mathrm{P}$ compounds. The experiment performed involved three factors: (i) P source $\left(\mathrm{KH}_{2} \mathrm{PO} 4\right.$ at $100 \mathrm{mg} \mathrm{kg}^{-1}$, and phosphate rock [PR] at 100 or $200 \mathrm{mg} \mathrm{kg}^{-1}$ ); (ii) plant inoculation with QST713 (inoculated and non-inoculated); and (iii) Fe oxide (ferrihydrite) in the growth medium (0 or $300 \mathrm{mg} \mathrm{kg}^{-1}$ concentration of citrate-ascorbate-extractable Fe). Ferrihydrite decreased dry matter yield in plants by more than $50 \%$. Inoculation with QST713 increased plant growth, and total accumulation of $\mathrm{P}$ by plants and $\mathrm{P}$ uptake, estimated as the total $\mathrm{P}$ in aerial parts and roots minus $P$ present in seeds. Overall, QST713 increased P uptake by $40 \%$, the effect being independent of the presence of ferrihydrite and $\mathrm{P}$ source. The increased $\mathrm{P}$ uptake observed can be ascribed to solubilization of $\mathrm{P}$ and to increased root growth. Therefore, QST713 improves P nutrition in plants grown on media with a high P adsorption capacity irrespective of the solubility of the P compound.
\end{abstract}

Key words: phosphorus, Bacillus subtilis, rhizosphere, Ca phosphates, Fe oxides.

\section{Introduction}

Although agricultural soils usually contain substantial amounts of total $\mathrm{P}, \mathrm{P}$ deficiency is a widespread problem in agriculture (Holford 1997, Wang et al. 2011) because most of total P is present as low plant-available forms owing to its reactions in soil (Delgado and Scalenghe 2008, Ryan et al. 2012). Among such reactions, precipitation of metal phosphates and $\mathrm{P}$ adsorption onto Al- and Fe-oxides, are known to play a crucial role in the dynamics and availability of this nutrient in soils (Schwertmann and Taylor 1989, Guzman et al. 1994, Saavedra and Delgado 2005). A high $P$ fixing capacity in soils such as those with high contents of Fe oxides decreases the efficiency of applied fertilizer in increasing P availability in soil (Ryan et al. 2012).

Today's agriculture relies on regular inputs of phosphate fertilizer derived from phosphate rock, a non-renewable, strategic resource (Whiters et al. 2014). The predicted future scarcity of which is raising fertilizer prices and emerging as a critical issue that may affect global food security in the near future (Gunther 2005, Cordell et al. 2009, Cordell and Neset 2014, Amundson et al. 2015). This requires an efficiently management of available $P$ resources (Simpson et al. 2011, Withers et al. 2014), through a better understanding of the biogeochemical cycle of $P$, the design of more rational fertilization schemes, as well as the use of more efficient biological resources such as crops with an increased capacity to use it (Kochian 2012, Heppell et al. 2015). The manipulation of the rhizosphere by inoculation with microorganisms capable of improving $\mathrm{P}$ nutrition of crops can also contribute to the efficient management of P resources (Patel et al. 2010, Wang et al. 2011, García-López et al. 2015).

Rhizosphere microbial communities can improve uptake of some nutrients such as $\mathrm{P}$ and hence it may contribute to overcome nutritional deficiencies (Aseri et al. 2008, Zuo and Zhang 2011, de Santiago et al. 2013). Some P-solubilizing microorganisms have been recommended for use as inoculants by virtue of their ability to increase P availability to plants by mobilizing P from scarcely available forms such as insoluble Ca phosphates or organic P forms naturally present in or applied to soil (Richardson 1994, 2001, Illmer et al. 1995, Whitelaw et al. 1999, Oliveira et al. 2009). Rhizospheric microorganisms can have additional benefits such as plant growth promotion (PGPR) or facilitating biocontrol of soil-borne diseases (Vassilev et al. 2006, de Santiago et al. 2011). The benefits of microbial inoculants on crops can provide a basis for their use in cost-effective integrated agricultural practices. Some commercial strains of Bacillus subtilis have proved effective PGPR and biocontrol agents (Yuan et al. 2012); others, have been found to facilitate solubilization of P compounds (Orhan et al. 2006, Mena-Violante and Olalde-Portugal 2007). 
Phosphorus availability to plants is related to the solubility of metal phosphates present in soil - Ca phosphates in alkaline soils, mainly - and to P desorption from sorbent surfaces such as Fe oxides. The action of P-mobilizing microorganisms may be affected by the sorption capacity of the growing medium and the solubility of $P$ forms in it. The influence of the solubility of $\mathrm{P}$ compounds may be better understood by elucidating the role of scarcely soluble Ca phosphates in calcareous media in supplying $\mathrm{P}$ to inoculated plants. These $\mathrm{P}$ compounds are major residual sources of $P$ unavailable to plants in calcareous soils. Although the literature on P-mobilizing organisms is growing steadily, there is still no unambiguous information about the main $\mathrm{P}$ forms being mobilized and how their mobilization is related to soil properties affecting $\mathrm{P}$ dynamics in soil, and particularly to Fe oxides. Microbial mechanisms enhancing Fe uptake by plants through dissolution of Fe minerals, such as release of complexing agents, acidification, or Fe(III) reduction (Lemanceau et al. 2009), may contribute to the uptake of P bound to Fe compounds by plants (Ghosh et al. 2015). Thus, an increased Fe uptake by inoculated plants with P-mobilizing microorganisms may reveal that improved $P$ nutrition is ascribed to the release of $P$ bound to Fe compounds. The main objective of this research was to understand the effect of inoculation with PGPR Bacillus subtilis QST713 on $P$ uptake by plants and whether the effect is influenced by the presence of Fe oxides (ferrihydrite) in the growing medium or the solubility of the P source applied. QST713 was selected because it is a commercial strain of $B$. subtilis effective in promoting plant growth and in the biocontrol of some relevant soil-borne diseases (Lahlali et al. 2011). Thus, evidence of its effectiveness as a P-mobilizing inoculant under adverse conditions (e.g., in media with scarcely soluble dominant $P$ forms and a high $P$ adsorption capacity) is bound to support its use in costeffective integrated management practices contributing to agricultural sustainability in the near future.

\section{Material and methods \\ Experimental design}

An experiment with cucumber plants (Cucumis sativus L. cv Tropico) grown in an artificial medium was performed. This type of medium was used to assess $\mathrm{P}$ mobilization from specific $\mathrm{P}$ forms because the wide range of compounds present in agricultural soils precludes identifying the origin of $\mathrm{P}$ absorbed by plants. The growing medium was a mixture of siliceous (70\%) and calcareous (30\%) sand. Before use, both sands were sieved between 0.5 and $1 \mathrm{~mm}$ to facilitate aeration and increase hydraulic conductivity. Siliceous sand was washed several times with diluted $\mathrm{Na}_{2} \mathrm{CO}_{3}$ to disperse and remove clay minerals and Fe oxides, whereas calcareous sand was washed with deionized water. The final $\mathrm{pH}$ of the growing medium, measured in water at a 1:2.5 growing medium/solution ratio, was 8.5 - a typical value for the calcareous soil the growing medium was intended to mimic.

The experiment, which was performed with 5 replications following a completely randomized design, involved three factors, namely: (i) P source, which was either a soluble form $\left(\mathrm{KH}_{2} \mathrm{PO}_{4}\right)$ applied at $100 \mathrm{mg} \mathrm{kg}^{-1}$ medium or an insoluble form (phosphate rock, PR; sieved at $0.1 \mathrm{~mm}$, and consisting mainly of apatite-type compounds) applied at two different rates (100 or $200 \mathrm{mg} \mathrm{kg}^{-1}$ ); (ii) plant inoculation with Bacillus subtilis (inoculated and noninoculated); and (iii) Fe oxide (ferrihydrite) in the growth medium ( 0 or $300 \mathrm{mg} \mathrm{kg}^{-1}$ citrate-ascorbate-extractable $\mathrm{Fe}$ ). Fe oxide enriched media were achieved by using part of the siliceous sand (180 g) coated with ferrihydrite according to Rahmatullah and Torrent (2000). Each experimental replication consisted of a cylindrical pot (polystyrene cylinder: $350 \mathrm{ml}, 5.5 \mathrm{~cm}$ diameter, $15 \mathrm{~cm}$ height) containing $0.4 \mathrm{~kg}$ of growing medium and with one plant of cucumber. Previously, seeds were germinated in peat and one plant was transplanted to each pot $15 \mathrm{~d}$ after germination. Plants were grown in a chamber under constant controlled environmental conditions, namely: a 14 h photoperiod, a $25 / 23{ }^{\circ} \mathrm{C}$ day/night temperature, $65 \% \mathrm{RH}$ and a $22 \mathrm{~W} \mathrm{~m}^{-2}$ light intensity. Plants were irrigated with a P-free Hoagland-type solution containing the following nutrients (all concentrations in mmol $\mathrm{I}^{-1}$ ): $\mathrm{MgSO}_{4}(2)$, $\mathrm{Ca}\left(\mathrm{NO}_{3}\right)_{2}(5), \mathrm{KNO}_{3}(5), \mathrm{KCl}(0.05)$, Fe-EDDHA (0.02), $\mathrm{H}_{3} \mathrm{BO}_{3}(0.024), \mathrm{MnCl}_{2}(0.0023), \mathrm{CuSO}_{4}(0.0005), \mathrm{ZnSO}_{4}(0.002)$ and $\mathrm{H}_{2} \mathrm{MoO}_{4}$ (0.0005). The $\mathrm{pH}$ of the nutrient solution was 6 .

The plants were inoculated with B. subtilis strain QST 713 (Serenade ASO, Bayer Cropscience) by adding $2 \times 10^{7}$ colony forming units (CFU) per kilogram of growing medium. To this end, a volume of $20 \mathrm{ml}$ of an aqueous suspension containing $410^{8} \mathrm{CFU} \mathrm{I}^{-1}$ was applied to the soil surface divided over four points around each plant after transplanting. Non-inoculated plants received an identical volume of de-ionized water that was applied in the same manner. The amount of nutrients supplied by the inoculant was negligible. Also, using Hoagland solution, which contains high nutrient concentrations, offset any potential differences in nutrient supply by effect of its rapidly replacing the solution in the sandy growing media after irrigation. 


\section{Plant analysis}

After 28 days of growth, plants were harvested, and the shoots and roots of each plant separated and dried at $65^{\circ} \mathrm{C}$ to constant weight in a forced-air oven. Then, dry matter (DM) in shoots and roots was measured, and P and Fe concentration in both organs were determined. To this end, dried plant material was ground to pass through a 1-mm sieve and an aliquot of $0.25 \mathrm{~g}$ was placed in a porcelain crucible for mineralization by dry combustion in a furnace at $550{ }^{\circ} \mathrm{C}$ for $8 \mathrm{~h}$. After combustion, the ash was dissolved in $10 \mathrm{ml} \mathrm{of} \mathrm{HCl}\left(1 \mathrm{~mol} \mathrm{I}^{-1}\right)$ and the resulting solution heated at $100^{\circ} \mathrm{C}$ for 15 min to recover all nutrients. Phosphorus in the digest was determined by using the colorimetric procedure of Murphy and Riley (1962), and Fe by atomic absorption spectrometry on a Unicam Solaar $M$ instrument from Thermo Fisher Scientific (Madrid, Spain). Certified material (1 sample in each combustion run) was also analysed in parallel to assess total recovery of nutrients present in the plant material. Total P uptake by plants was estimated as that present in plant tissues minus that in seeds.

\section{Growing medium analysis}

Alkaline phosphatase activity at the end of the experiment was determined in the rhizospheric growth medium according to Tabatabai and Bremner (1969), i.e., as the amount of PNP ( $p$-nitrophenol) formed from pNPP (p-nitrophenyl phosphate).

Organic anions (OA) were extracted from rhizospheric soil by shaking an amount of $5 \mathrm{~g}$ of sample with $5 \mathrm{ml}$ of $\mathrm{NaOH}\left(0.1 \mathrm{~mol} \mathrm{I}^{-1}\right)$ at $4 \mathrm{~Hz}$ during $1.5 \mathrm{~h}$ (Baziramakenga et al. 1995, Radersma and Grierson 2004). After shaking, suspensions were centrifuged at 10,000 $\mathrm{g}$ for $10 \mathrm{~min}$ and the supernatants were filtered through Whatman 42 filter paper. The filtrate from each $\mathrm{NaOH}$ extract was acidified to $\mathrm{pH} 2-3$ with $\mathrm{H}_{2} \mathrm{SO}_{4}\left(1 \mathrm{~mol} \mathrm{I}^{-1}\right)$ and the supernatant passed through a filter of $0.45 \mu \mathrm{m}$ pore size. Organic anions were separated by high performance liquid chromatograph (HPLC) on an HPLC Varian ProStar 410 instrument furnished with a C18 column (Varian, $250 \mathrm{~mm}$ $\times 34.6 \mathrm{~mm}, 8 \mu \mathrm{m}$ particle size), using isocratic elution with $98 \%$ of $\mathrm{H}_{2} \mathrm{SO}_{4}\left(5 \mathrm{mmol} \mathrm{l}^{-1}\right)$ at $\mathrm{pH} 2 \mathrm{plus} 2 \%$ methanol at $0.8 \mathrm{ml} \mathrm{min} \mathrm{m}^{-1}$ as carrier solution and a $20 \mu$ injected volume. Organic anions were detected at $215 \mathrm{~nm}$, using a Varian 486 photo-diode array detector. Individual standard solutions of acetic, oxalic, citric, malic, fumaric and succinic acid, all from Sigma (Barcelona, Spain), were also used.

At the end of the experiments, the density of Bacillus spp in each rhizospheric medium was determined by dilution plating. Bacillus spp were isolated on nutrient-agar medium after heating the suspension at $80^{\circ} \mathrm{C}$ for 10 min according to Tuitert et al. (1998).

\section{Statistical analysis}

The effect of microorganisms on the different measured variables was assessed by analysis of variance (ANOVA), using the General Linear Model (GLM) in the software Statgraphics Plus 5.1 (StatPoint 2000). Differences between means were assessed with Tukey's test at $p<0.05$. Significant interactions between factors precluded evaluation of main effects in a combined analysis and hence comparing means between treatments for each main factor. When interactions were significant, mean comparison for the combined effect of factors was performed as recommended by Borrero et al. (2012) and de Santiago et al. (2013). Normality and homoscedasticity were always previously ascertained by using the Smirnoff-Kolmogorov and Levene test, respectively (Acutis et al. 2012), and data transformed when either or both tests were not passed. Regressions were also done with Statgraphics Plus 5.1.

\section{Results}

As expected, application of the most soluble $\mathrm{P}$ form $\left(\mathrm{KH}_{2} \mathrm{PO} 4\right)$ increased $\mathrm{P}$ concentration in shoots and roots, total $P$ in shoots and roots and $P$ uptake (Tables 1 and 2). Enriching the growing medium with ferrihydrite resulted in markedly decreased root growth, total P content in roots and shoots, and P uptake. In contrast ferrihydrite resulted in significantly increased $P$ concentration in roots and shoots, and accumulation of organic anions (OA) in the medium. Significant interactions between ferrihydrite enrichment and P source were observed for total P content in shoots, P uptake, and total Fe and total dry matter in shoots (Table 1). The effect on total P and Fe in shoots was only significant with $\mathrm{KH}_{2} \mathrm{PO}$, whereas that on DM yield was significant with both this $\mathrm{P}$ source and PR at $100 \mathrm{mg} \mathrm{kg}^{-1}$ (Table 3). Overall, the most negative consequences of enriching the growing media with Fe were observed with $\mathrm{P}$ applied in its most soluble form. None of the factors studied affected hydrolytic enzyme activity or CFU in the rhizosphere at the end of the experiment (Table 1). Inoculation with B. subtilis significantly increased DM yield in roots (Tables 1 and 2 ). The microorganism significantly increased total $P$ in shoots and roots, and also total $\mathrm{P}$ uptake (Tables 1 and 2); in fact, $\mathrm{P}$ uptake was increased by $40 \%$ on average relative to the control without inoculation (Table 2). By contrast, the effects of $B$. subtilis on P concentration in plants were not significant (Table 1). 


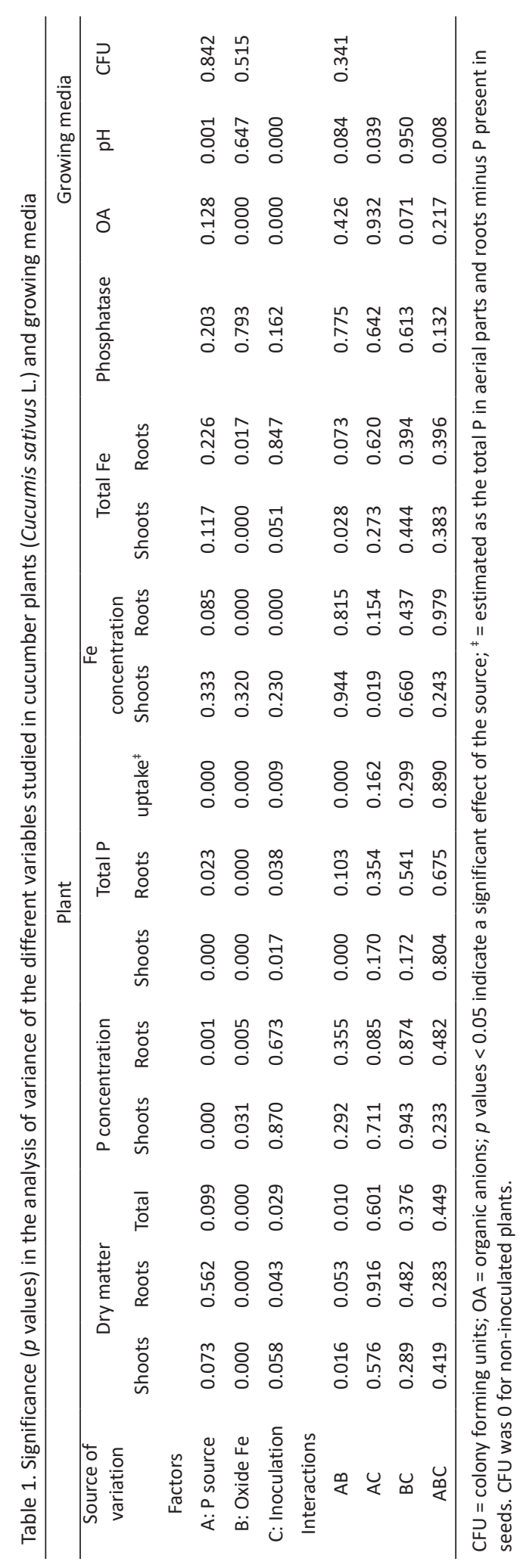

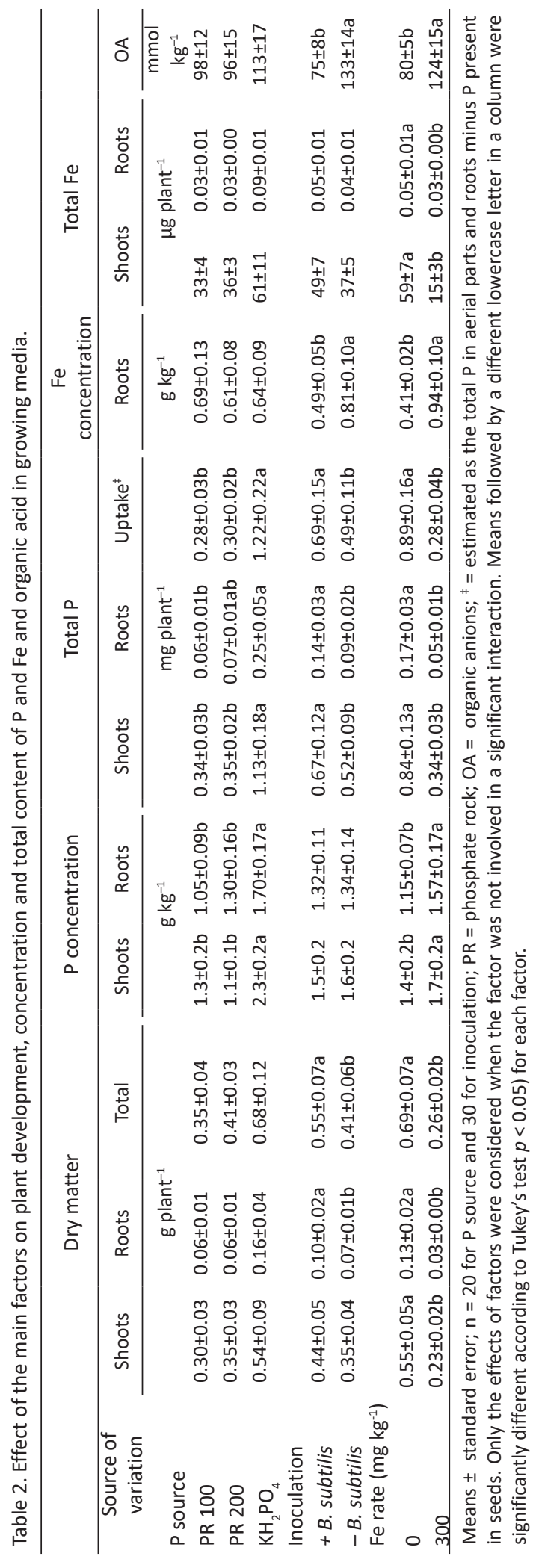


Bacillus subtilis decreased organic acid accumulation in rhizospheric soil by $43 \%$ relative to non-inoculated plants (Table 2). Inoculation, however, had no significant effect on phosphatase hydrolytic activity in the rhizosphere.

Table 3. Effect of the interaction between P source and Fe rate on various properties of the plants and growing media

\begin{tabular}{|c|c|c|c|c|c|c|c|}
\hline \multirow{3}{*}{$\begin{array}{c}P \\
\text { source }\end{array}$} & \multirow[b]{2}{*}{$\begin{array}{c}\text { Fe rate } \\
\left(\mathrm{mg} \mathrm{kg}^{-1}\right)\end{array}$} & \multicolumn{2}{|c|}{ Dry matter } & \multicolumn{3}{|c|}{ Total Phosphorus } & \multirow{2}{*}{$\begin{array}{c}\text { Total Fe } \\
\text { Shoots }\end{array}$} \\
\hline & & Total & Shoots & Shoots & Roots & P uptake & \\
\hline & & \multicolumn{2}{|c|}{ g plant $^{-1}$} & \multicolumn{3}{|c|}{$\mathrm{mg} \mathrm{plant}^{-1}$} & $\mu$ g plant $^{-1}$ \\
\hline \multirow[t]{2}{*}{ PR 100} & 0 & $0.47 \pm 0.05 b$ & $0.39 \pm 0.04 b$ & $0.39 \pm 0.04 b$ & $0.08 \pm 0.01 b c$ & $0.36 \pm 0.05 b$ & $41.04 \pm 5.63 b$ \\
\hline & 300 & $0.24 \pm 0.03 c$ & $0.2 \pm 0.03 c$ & $0.28 \pm 0.03 b$ & $0.04 \pm 0.01 c$ & $0.2 \pm 0.03 b$ & $23.7 \pm 4.22 b$ \\
\hline \multirow[t]{2}{*}{ PR 200} & 0 & $0.52 \pm 0.02 \mathrm{ab}$ & $0.44 \pm 0.02 \mathrm{ab}$ & $0.39 \pm 0.02 b$ & $0.08 \pm 0.01 b$ & $0.36 \pm 0.03 b$ & $41.6 \pm 2.42 \mathrm{ab}$ \\
\hline & 300 & $0.3 \pm 0.04 b c$ & $0.26 \pm 0.03 b c$ & $0.31 \pm 0.03 b$ & $0.05 \pm 0.01 b c$ & $0.25 \pm 0.04 b$ & $29.96 \pm 5.07 b$ \\
\hline \multirow[t]{2}{*}{$\mathrm{KH}_{2} \mathrm{PO}_{4}$} & 0 & $1.07 \pm 0.12 \mathrm{a}$ & $0.83 \pm 0.09 a$ & $1.73 \pm 0.17 a$ & $0.38 \pm 0.05 a$ & $1.96 \pm 0.21 a$ & $94.4 \pm 13.79 a$ \\
\hline & 300 & $0.24 \pm 0.05 c$ & $0.22 \pm 0.04 c$ & $0.45 \pm 0.09 \mathrm{~b}$ & $0.07 \pm 0.04 b c$ & $0.39 \pm 0.11 b$ & $23.76 \pm 5.21 b$ \\
\hline
\end{tabular}

Mean \pm standard error, $\mathrm{n}=10 ; \mathrm{PR}=$ phosphate rock; ${ }^{\ddagger}=$ estimated as the total $\mathrm{P}$ in aerial parts and roots minus $\mathrm{P}$ present in seeds Means followed by a different lowercase letter in a column were significantly different according to Tukey's test at a $p<0.05$ (for combinations of treatments)

Table 4. Effect of the significant interaction between P source and inoculation with Bacillus subtilis on Fe concentration in shoots and $\mathrm{pH}$ in growing media

\begin{tabular}{lccc}
\hline & & Fe concentration & $\mathrm{pH}$ \\
\hline P source & Inoculation & Shoots $\left(\mathrm{mg} \mathrm{kg}^{-1}\right)$ & \\
PR 100 & + B.subtilis & $104 \mathrm{ab}$ & $9.33 \mathrm{bc}$ \\
& - B.subtilis & $106 \mathrm{ab}$ & $9.66 \mathrm{a}$ \\
$\mathrm{PR} 200$ & + B.subtilis & $96 \mathrm{ab}$ & $9.27 \mathrm{c}$ \\
& - B.subtilis & $107 \mathrm{ab}$ & $9.36 \mathrm{bc}$ \\
$\mathrm{KH}_{2} \mathrm{PO}_{4}^{+}$ & + B.subtilis & $137 \mathrm{a}$ & $9.26 \mathrm{c}$ \\
& - B.subtilis & $94 \mathrm{~b}$ & $9.47 \mathrm{ab}$ \\
\hline
\end{tabular}

Mean, $n=10 ; P R=$ phosphate rock; Means followed by a different lowercase letter in a column were significantly different according to Tukey's test at $p<0.05$ (for combinations of treatments)

The effect of the microorganism on Fe concentration in shoots was found to depend on $\mathrm{P}$ source as revealed by the significant interaction between both factors (Table 1); this was especially so with $\mathrm{P}$ applied as $\mathrm{KH}_{2} \mathrm{PO}_{4}\left(\mathrm{Table}_{4}\right)$. The effect of the microorganism on soil $\mathrm{pH}$ in the rhizosphere was also dependent of $\mathrm{P}$ source (Table 1), and significant with $\mathrm{KH}_{2} \mathrm{PO}_{4}$ and with $\mathrm{PR}$ at $100 \mathrm{mg} \mathrm{kg}^{-1}$ (Table 4).

Phosphorus uptake was related to total Fe in plants (data normalized by logarithmic transformation; $R^{2}=0.33$; $p<0.001)$. However, the relationship was highly significant for inoculated plants, but very weak for non-inoculated plants (Fig. 1). Phosphorus uptake and total Fe in plants were related to DM in roots $\left(R^{2}=0.52\right.$ and $R^{2}=0.43$, respectively; both $p<0.001$ ); there was, however, no significant differences in the regressions between inoculated and non-inoculated plants (results not shown). 


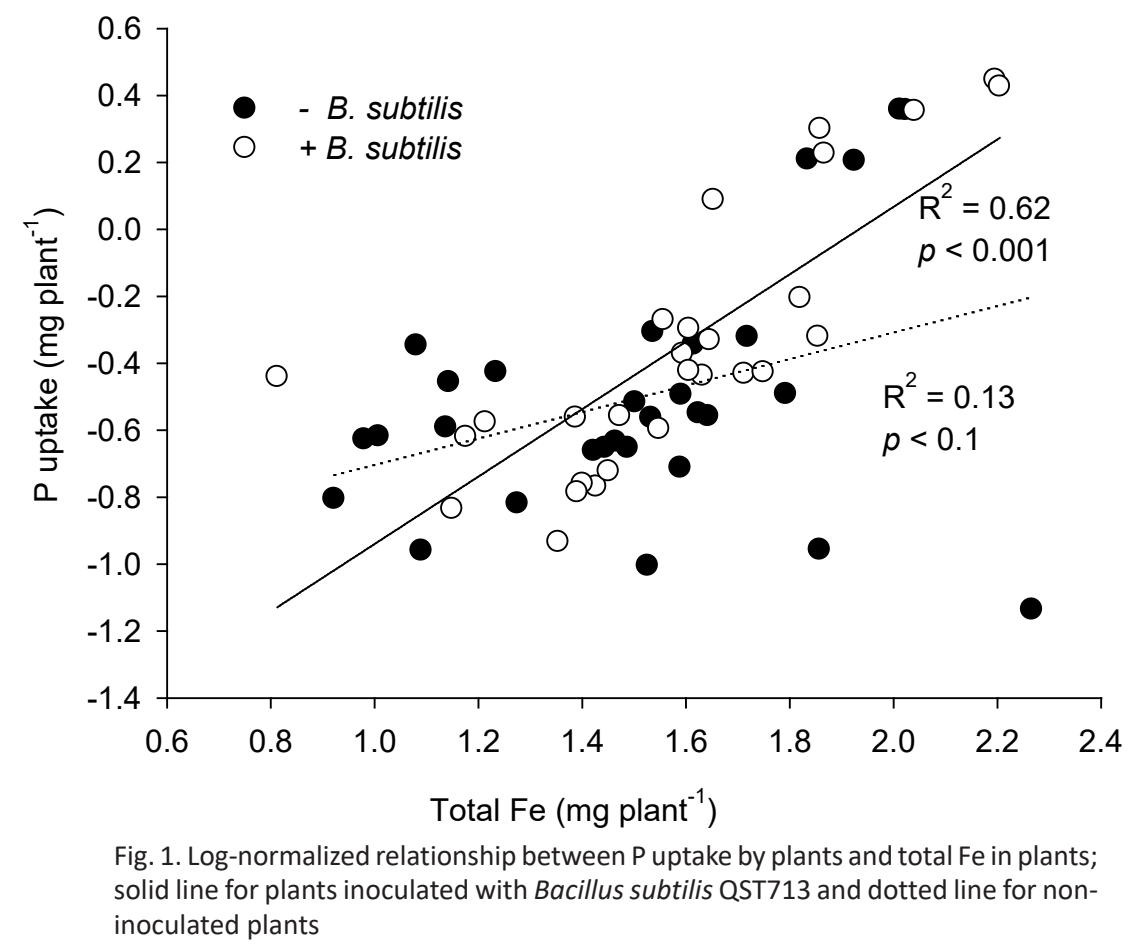

\section{Discussion}

Phosphorus availability to plants was found to be restricted to a similar extent by a poorly soluble P source and by the presence of sorbent surfaces (Fe oxides) in the media when P was applied as soluble phosphate (Table 3). Despite the decreased amount of Fe oxides present in the growing media relative to natural soils, unsaturation of sorbent sites on Fe oxides considerably reduced the efficiency of applied P. This finding confirms that solubilization of insoluble $\mathrm{P}$ forms or blocking of $\mathrm{P}$ applied to sorbent surfaces has crucial effects on $\mathrm{P}$ uptake by plants and hence on fertilizer efficiency. Based on the results, P from poorly soluble forms, which are gradually released through mobilizing mechanisms acting in the rhizosphere, is less prone to irreversible adsorption onto sorbent surfaces than are soluble P forms.

Inoculation with B. subtilis QST713 proved efficient towards mobilizing P; thus, total P in shoots and roots, and $P$ uptake, were increased relative to the control without inoculation irrespective of $P$ source and the presence of sorbent surfaces. This is consistent with the well-known P-mobilizing abilities of other strains of this microorganism (Roi et al. 2004, Orhan et al. 2006, Mena-Violante and Olalde-Portugal 2007). Based on our results, mobilization seemingly resulted at least partially from its acidifying effect; thus, the microorganism lowered the $\mathrm{pH}$ slightly in two of the three P treatments. However, the increased P uptake with B. subtilis QST713 in inoculated media enriched with ferrihydrite suggests that the potential benefits of the microorganism for $P$ use by may be in part due to blocking of sorption sites on Fe oxides through release of organic compounds forming stable complexes such as siderophores with Fe; in fact, other strains of this microorganism are known to release such compounds as a Fe-mobilizing strategy (Sansinenea and Ortiz 2011, Zhao et al. 2011, Walia et al. 2014). These organic compounds compete for sorption sites with $\mathrm{P}$, thus decreasing $\mathrm{P}$ adsorption and increasing $\mathrm{P}$ absorption by plants. The hypothesis of a siderophore-mediated increased $\mathrm{P}$ availability is supported by the evidence of increased Fe accumulation in shoots with $B$. subtilis QST713 when increased amounts of $P$ were adsorbed on Fe oxides, i.e. with $\mathrm{KH}_{2} \mathrm{PO}_{4}$ (Table 4). Microbial siderophores are known to increase Fe uptake by plants (de Santiago et al. 2013). Also, $P$ adsorption onto Fe oxides is known to decrease Fe uptake by plants by preventing adsorption of Fe-complexing organic compounds and hindering P dissolution as a result (Sánchez-Rodríguez et al. 2013). However, the increased Fe concentration in shoots in inoculated plants when $\mathrm{P}$ source was $\mathrm{KH}_{2} \mathrm{PO}_{4}$ and the increasing trend in total Fe in shoots $(p=0.0506)$ suggest that microbial siderophores are more efficient in competing for sorption sites on $\mathrm{Fe}$ oxides with $\mathrm{P}$ than Fe-complexing compounds released by plants. On the other hand, the decreased concentration of low-molecular weight organic acids in inoculated media suggests that the nature of these microbial 
Fe-mobilizing compounds is different from the OA excreted by roots. The compounds, usually referred to as "siderophores", are especially efficient and specific in complexing Fe relative to low-molecular organic acids excreted by plants (de Santiago et al. 2009, 2013).

Bacillus subtilis QST713 was effective in improving growth of cucumber plants measured as total DM . The increased growth may have been the consequence of enhanced plant nutrition. The assumption that $P$ availability influences DM yield is supported by the fact that Fe oxides restricted the uptake by plants of applied P. P adsorption on Fe oxides implies that part of adsorbed $P$ remains unavailable to plants (Delgado and Scalenghe 2008). Thus, $P$ adsorption on Fe oxides results in decreased $\mathrm{P}$ concentration in solution and uptake by plants in Fe-enriched media. This explaines the lower DM yield in Fe-enriched media when compare with media without Fe oxides. However, increasing root growth is a common plant strategy for improving P uptake in P-deficient media (Sun et al. 2014, Wang et al. 2014); also, it is consistent with the positive relationship between root DM and P uptake by plants in observed this work. The increase in root DM resulting from the presence of $B$. subtilis was independent on any factors affecting $\mathrm{P}$ availability in the growing medium (viz., $\mathrm{P}$ source or ferrihydrite). Therefore, $B$. subtilis increased plant growth - more markedly in roots (43\%) than in shoots $(29 \%)$ - in media with a high or low $P$ availability. This suggests that $B$. subtilis plays a direct role in increasing DM yield that is not necessarily mediated by improved $P$ availability to plants. Thus, the enhanced root growth with $B$. subtilis QST713 increases $P$ uptake by plants irrespective of the $P$ availability level in the growing medium. This assumption is consistent with previous evidence of improved growth in plants inoculated with other $B$. subtilis strains resulting from their production of auxins (Roi et al. 2004, Lim and Kim 2009). The results are also consistent with those of Orhan et al. (2006) and Turan et al. (2007), who found other Bacillus strains to increase P uptake through improved root growth.

Organic anions exudation is one response of microorganisms and plants to P scarcity in the growing medium (Jones 1998, Walker et al. 2003). Also, exudation of organic anions by cucumber roots is known to be a mobilizing strategy triggered under nutrient deficiency conditions (Kamilova et al. 2006). This may account for the increased organic anion concentrations observed here when $P$ availability to plants was decreased by application of ferrihydrite (Table 2). The fact that oxalate was the only organic anion detetected in most of the growing media (results not shown) is consistent with previous works showing that this compound is the main anion released by plant roots under P-deficient conditions (Jones 1998, Ström et al. 2005). Organic anions released by plants or bacteria can compete for sorption sites and facilitate $\mathrm{P}$ desorption as a result; also they can enhance dissolution of sparingly soluble phosphates (Ström et al. 2002, 2005). However, inoculation with B. subtilis decreased the concentration of organic acids in the rhizospheric medium. This can be ascribed to consumption of this $C$ source by $B$. subtilis QST713, which is consistent with previous evidence that inoculation with microorganisms can decrease the concentration of OA in the rhizosphere (García-López et al. 2015). Therefore, the benefits of B. subtilis QST713 on P nutrition of plants cannot be ascribed to the production of low-molecular weight organic acids; rather, the acids exuded by plant roots can indirectly improve $\mathrm{P}$ uptake by plants by acting as $\mathrm{C}$ sources for the microorganism.

Low-molecular organic acids play a prominent role in an Fe acquisition strategy for dicotyledonous plants. Thus, the decreased organic anions concentrations observed with QST713 provide additional evidence for its contribution to Fe uptake by plants via other, more effective Fe-mobilizing mechanisms such as the above-described release of siderophores. A significant relationship between $\mathrm{P}$ uptake and total $\mathrm{Fe}$ in plants was observed with $B$. subtilis but not in non-inoculated plants (Fig. 1). This likely reveal that different mechanisms affecting $F e$ and $P$ availability to plants may be involved when plants are inoculated with QST713. Thus, P uptake in inoculated plants was more significantly related to Fe uptake than it was in non-inoculated plants (Fig. 1). This result suggests that P mobilization in inoculated media is more markedly dependent on Fe-mobilizing mechanisms than it is in non-inoculated media.

\section{Conclusions}

Bacillus subtilis QST713 was effective in increasing P uptake by plants irrespective of the solubility of the P source applied or the adsorption capacity of the growing medium. This benefit on P uptake can be ascribed to an increased $\mathrm{P}$ mobilization from growing media and to an enhanced root growth. The increased Fe accumulation in plants grown in ferrihydrite-enriched media reveals a link between Fe and P acquisition strategies, and also that $\mathrm{P}$ uptake is improved by adsorption of siderophores onto Fe oxides. 


\section{Acknowledgement}

This work was funded by the Spanish Ministry of Science and Innovation and the European Regional Development Fund of the European Union through the National Research, Development and Innovation Programme (Plan Nacional I+d+i, AGL2011-29893-CO2-01). Bacillus subtilis QST713 was kindly supplied by Bayer Cropscience.

\section{References}

Acutis, M., Scaglia, B. \& Confalonieri, R. 2012. Perfunctory analysis of variance in agronomy, and its consequences in experimental results interpretation. European Journal of Agronomy 43: 129-135.

Amundson, R., Berhe, A.A., Hopmans, J.W., Olson, C., Sztein, E. \& Sparks, D.L. 2015. Soil and human security in the 21st century. Science 348: 6235.

Aseri, G.K., Jain, N., Panwar, J., Rao, A.V. \& Meghwal, P.R. 2008. Biofertilizers improve plant growth, fruit yield, nutrition, metabolism and rhizosphere enzyme activities of Pomegranate (Punica granatum L.) in Indian Thar Desert. Scientia Horticulturae 117: 130-135.

Baziramakenga, R., Simard, R.R. \& Leroux, G.D. 1995. Determination of organic acids in soil extracts by ion chromatography. Soil Biology and Biochemistry 27: 349-356.

Borrero, C., Trillas, I., Delgado, A. \& Avilés, M. 2012. Effect of ammonium/nitrate ratio in nutrient solution on control of Fusarium wilt of tomato by Trichoderma asperellum T34. Pathology 61: 132-139.

Cordell, T. \& Neset, S.S. 2014. Phosphorus vulnerability: A qualitative framework for assessing the vulnerability of national and regional food systems to the multi-dimensional stressors of phosphorus scarcity. Global Environmental Change 24: 108-122.

Cordell, D., Drangert, J-O. \& White, S. 2009. The story of phosphorus: Global food security and food for thought. Global Environmental Change 19: 293-305.

de Santiago, A., García-López, A.M., Quintero, J.M., Avilés, M. \& Delgado, A. 2013. Effect of Trichoderma asperellum strain T34 and glucose addition on iron nutrition in cucumber grown on calcareous soils. Soil Biology and Biochemistry 57: 598-605.

de Santiago, A., Quintero, J. M., Avilés, M. \& Delgado, A. 2011. Effect of Trichoderma asperellum strain T34 on iron, copper, manganese, and zinc uptake by wheat grown on a calcareous medium. Plant and Soil 342: 97-104.

de Santiago, A., Quintero, J.M., Avilés, M. \& Delgado, A. 2009. Effect of Trichoderma asperellum strain T34 on iron nutrition in white lupin. Soil Biology and Biochemistry 41: 2453-2459.

Delgado, A. \& Scalenghe, R. 2008. Aspects of phosphorus transfer from soils in Europe. Journal of Plant Nutrition and Soil Science 171: 552-575.

García-López, A.M., Avilés, M. \& Delgado, A. 2015. Plant uptake of phosphorus from sparingly available P-sources as affected by Trichoderma asperellum T34. Agricultural Food Science 24: 249-260.

Ghosh, P., Rathinasabapathi, B. \& Ma, Q.M. 2015. Phosphorus solubilization and plant growth enhancement by arsenic-resistant bacteria. Chemosphere 134: 1-6.

Gunther, F. 2005. A solution to the heap problem: the doubly balanced agriculture: integration with population. http://www.holon.se/folke/kurs/Distans/Ekofys/Recirk/Eng/balanced.shtml.

Guzman, G., Alcantara, E., Barron, V. \& Torrent, J. 1994. Phytoavailability of phosphate adsorbed on ferrihydrite, hematite, and goethite. Plant and Soil 159: 219-225.

Heppell, J., Payvandi, S., Talboys, P., Zygalakis, K.C., Fliege, J., Langton, D., Sylvester-Bradley, R., Walker, R., Jones, D.L. \& Roose, T. 2015. Modelling the optimal phosphate fertiliser and soil management strategy for crops. Plant and Soil DOI 10.1007/s11104015-2543-0.

Holford, I.C.R. 1997. Soil phosphorus: Its measurement, and its uptake by plants. Australian Journal of Soil Research 35: 227-239.

Jones, D.L. 1998. Organic acids in the rhizosphere-a critical review. Plant and Soil 205: 25-44.

Kamilova, F., Kravchenko, L.V., Shaposhnikov, A.I., Azarova, T., Makarova, N. \& Lugtenberg, B. 2006. Organic acids, sugars, and Ltryptophan in exudates of vegetables growing on stonewool and their effects on activities of rhizosphere bacteria. Molecular Plant-Microbe Interactions 19: 250-256.

Kochian, L.V. 2012. Plant nutrition: Rooting for more phosphorus. Nature 488: 466-467.

Lahlali, R., Peng, G., McGregor, L., Gossen, B.D., Hwang, S.F. \& McDonald, M. 2011. Mechanisms of the biofungicide Serenade (Bacillus subtilis QST713) in suppressing clubroot. Biocontrol Science and Technology 21: 1351-1362.

Lemanceau, P., Bauer, P., Kraemer, S. \& Briat, J.F. 2009. Iron dynamics in the rhizosphere as a case study for analyzing interactions between soils, plants and microbes. Plant Soil 321: 513-535.

Lim, J.H. \& Kim, S.D. 2009. Synergistic plant growth promotion by the indigenous auxins-producing PGPR Bacillus subtilis AH18 and Bacillus licheniforims K11. Journal Of The Korean Society For Applied Biological Chemistry 52: 531-538.

Illmer, P., Barbato, A. \& Schinner, F. 1995. Solubilization of hardly soluble $\mathrm{AlPO}_{4}$ with P-solubilizing microorganisms. Soil Biology and Biochemistry 27: 265-270.

Mena-Violante, H.G. \& Olalde-Portugal, V. 2007. Alteration of tomato fruit quality by root inoculation with plant growth-promoting rhizobacteria (PGPR): Bacillus subtilis BEB-13bs. Scientia Horticulturae 113: 103-106.

Murphy, J. \& Riley, J.P. 1962. A modified single solution method for the determination of phosphate in natural waters. Analitica Chimica Acta 27: 31-36. 
Oliveira, C.A., Alves, V.M.C., Marriel, I.E., Gomes, E.A., Scotti, M.R., Carneiro, N.P., Guimaraes, C.T., Schaffert, R.E. \& Sa, N.M.H. 2009. Phosphate solubilizing microorganisms isolated from rhizosphere of maize cultivated in an oxisol of the Brazilian Cerrado Biome. Soil Biology and Biochemistry 41: 1782-1787.

Orhan, E., Esitken, A., Ercisli, S., Turan, M. \& Sahin, F. 2006. Effects of plant growth promoting rhizobacteria (PGPR) on yield, growth and nutrient contents in organically growing raspberry. Scientia Horticulturae 111: 38-43.

Patel, K.J., Singh, A.K., Nareshkumar, G. \& Archana, G. 2010. Organic-acid-producing, phytate-mineralizing rhizobacteria and their effect on growth of pigeon pea (Cajanus cajan). Applied Soil Ecology 44: 252-261.

Radersma, S. \& Grierson, P.F. 2004. Phosphorus mobilization in agroforestry: Organic anions, phosphatase activity and phosphorus fractions in the rhizosphere. Plant and Soil 259: 209-219.

Rahmatullah \& Torrent, J. 2000. Phosphorus dynamics and uptake by wheat in a model calcite-ferrihydrite system. Soil Science 165: 803-812.

Richardson, A.E. 1994. Soil microorganisms and phosphorus availability. In: Pankhurst, C.E. et al. (eds.) Soil Biota Management in Sustainable Farming System. Victoria, Australia: CSIRO. p 50-62.

Richardson, A.E. 2001. Prospects for using soil microorganisms to improve the acquisition of phosphorus by plants. Australian Journal of Plant Physiology 28: 897-906.

Roi, A., Reva, O.N., Kurdish, I.K. \& Smirnov, V.V. 2004. Biological properties of the phosphorus-mobilizing Bacillus subtilis strain IMV V-7023. Applied Microbiology and Biotechnology 40: 476-481.

Ryan, J., Ibrikci, H., Delgado, A., Torrent, J., Sommer, R. \& Rashid, A. 2012. Significance of phosphorus for agriculture and environment in the West Asia and North Africa region. Advances in Agronomy 114: 91-153.

Saavedra, C. \& Delgado, A. 2005. Phosphorus fractions and release patterns in typical Mediterranean soils. Soil Science Society of America Journal 69: 607-615.

Sanchez-Rodriguez, A.R., del Campillo, M.C. \& Torrent, J. 2013. Phosphate aggravates iron chlorosis in sensitive plants grown on model calcium carbonate-iron oxide systems. Plant and Soil 373: 31-42.

Sansinenea, E. \& Ortiz, A. 2011. Secondary metabolites of soil Bacillus spp. Biotechnology Letters 33:1523-1538.

Schwertmann, U. \& Taylor, R.M. 1989. Iron oxides. In: Dixon, J.B. \& Weed, S.B. (eds.) Minerals in Soil Environments, 2nd ed. Madison, USA: Soil Science Society of America Book Ser. No. 1. p. 379-438.

Simpson, R.J., Oberson, A., Culvenor, R.A., Ryan, M.H., Veneklaas, E.J., Lambers, H., Lynch, J.P., Ryan, P.R., Delhaize, E. \& Smith, F.A. 2011. Strategies and agronomic interventions to improve the phosphorus-use efficiency of farming systems. Plant and Soil 349: 1-32. StatPoint 2000. Statgraphics Plus 5.1. Rockville, Maryland.

Ström, L., Owen, A.G., Godbold, D.L. \& Jones, D.L. 2002. Organic acid mediated P mobilization in the rhizosphere and uptake by maize roots. Soil Biology and Biochemistry 34: 703-710.

Ström, L., Owen, A.G., Godbold, D.L. \& Jones, D.L. 2005. Organic acid behaviour in a calcareous soil implications for rhizosphere nutrient cycling. Soil Biology and Biochemistry 37: 2046-2054.

Sun, H., Tao, J., Liu, S., Huan, S., Chen, S., Xie, X., Yoneyama, K., Zhan, Y. \& Xu, G. 2014. Strigolactones are involved in phosphateand nitrate-deficiency induced root development and auxin transport in rice. Journal of Experimental Botany 65: 6735-46. doi:10.1093/jxb/eru029.

Tabatabai, M.A. \& Bremner, J.M. 1969. Use of $p$-nitrophenyl phosphate for assay of soil phosphatase activity. Soil Biology and Biochemistry 1: 301-307.

Tuitert, G., Szczech, M. \& Bollen, G.J. 1998. Suppression of Rhizoctonia solani in potting mixtures amended with compost made from organic household waste. Phytopathology 88: 764-773.

Turan, M., Ataoğlu, N. \& Şahin, F. 2007. Effects of Bacillus FS-3 on growth of tomato (Lycopersicon esculentum L.) plants and availability of phosphorus in soil. Plant Soil and Environment 53: 58-64.

Vassilev, N., Vassileva, M. \& Nikolaeva, I. 2006. Simultaneous P-solubilizing and biocontrol activity of microorganisms: potentials and future trends. Applied Microbiology Biotechnology 71: 137-144.

Walia, A., Mehta, P., Chauhan, A. \& Shirkot, C.K. 2014. Effect of Bacillus subtilis strain CKT1 as inoculum on growth of tomato seedlings under net house conditions Proceedings of the National Academy of Sciences, India - Section B: Biological Sciences 84: 145-155.

Walker, T.S., Bais, H.P., Grotewold, E. \& Vivanco, J.M. 2003. Root exudation and rhizosphere biology. Plant Physiology 132: 44-51.

Wang, S., Zhang, S., Sum, C.D., Xu, Y.X., Chen, Y., Chenliang, Y., Qian, Q., Jian, D.A. \& Qi Y.H. 2014. Auxin response factor (OsARF12), a novel regulator for phosphate homeostasis in rice (Oryza sativa). New Phytologist 201: 91-103.

Wang, J.B., Chen, Z.H., Chen, L.J., Zhu, A.N. \& Wu, Z.J. 2011. Surface soil phosphorus and phosphatase activities affected by tillage and crop residue input amounts. Plant Soil and Environment 57: 251-257.

Whitelaw, M.A., Harden, T.J. \& Helyar, K.R. 1999. Phosphate solubilisation in solution culture by the soil fungus Penicillium radicum. Soil Biology and Biochemistry 31: 655-665.

Withers, P.J.A., Sylvester-Bradley, R., Jones, D.L., Healey, J.R. \& Talboys, P.J. 2014. Feed the crop not the soil: rethinking phosphorus management in the food chain. Environmental Science and Technology 48: 6523-6530.

Yuan, J., Raza, W., Huang, Q. \& Shen, Q. 2012. The ultrasound-assisted extraction and identification of antifungal substances from B. Amyloliquefaciens strain NJN-6 suppressing Fusarium oxysporum. Journal of Basic Microbiology 52: 721-730.

Zhao, Q., Shen, Q., Ran, W., Xiao, T., Xu, D. \& Xu, Y. 2011. Inoculation of soil by Bacillus subtilis Y-IVI improves plant growth and colonization of the rhizosphere and interior tissues of muskmelon (Cucumis melo L.). Biology and Fertility of Soils 47: 507-514.

Zuo, Y. \& Zhang, F. 2011. Soil and crop management strategies to prevent iron deficiency in crops. Plant and Soil 339: 83-95. 